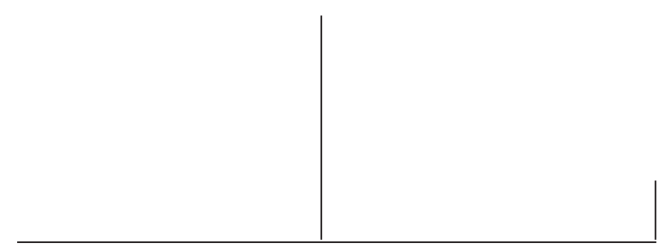

Rev. Latinoam. Psicopat. Fund., V, 1, 99-110

\title{
A psicanálise e os psicofármacos nas depressões
}

\author{
Urania Tourinho Peres
}

Através de um breve histórico do surgimento e desenvolvimento dos antidepressivos, vamos chegar a um confronto entre as duas linhas de abordagem das depressões, consideradas como a "doença”, por excelência, do homem contemporâneo. A psicanálise tendo como ponto de partida a noção de conflito e a psiquiatria uma insuficiência biológica, um deficit de neurotransmissores. Assim, duas linhas de raciocínio se desenvolvem marcando distintas posições, uma privilegiando a subjetividade do paciente e a outra a procura de uma objetividade científica.

Interrogamo-nos como a psicanálise deve situar-se frente a crescente medicalização da vida e os avanços da neurobiologia, e vamos apresentar um caminho teórico que nos é facilitado por Jacques Lacan marcando a distinção entre a transferência e a sugestão.

Palavras-chave: Psicanálise, psiquiatria, transferência, sugestão, conflito, neurotransmissores 


\section{À parte isso, a ciência tem tão pouco a nos dizer sobre a origem da sexualidade, que podemos comparar o problema a uma escuridão em que nem mesmo o raio de luz de uma hipótese penetrou.}

(S. Freud, “Além do princípio do prazer", p. 78)

Vivemos um momento em que a medicalização da vida tem uma carreira vertiginosa. Hoje pode-se tomar pílulas para dormir, emagrecer, manter a juventude, recuperar a memória, a atenção, melhorar o desempenho sexual e, o que é mais interessante, para atingir o bem-estar, ser mais produtivo no trabalho; em suma, para desfrutar felicidade. Curiosamente, vivemos também um momento onde a depressão ou as depressões se constituem como o mais intenso e dominante sofrimento íntimo do ser humano. Será essa a manifestação que mais nos fala do homem nesse final de século, que mais evidencia as mutações de nossa subjetividade, que nos revela, como a histeria nos revelou em fins do século passado?

A verdade é que, entre 1965 e 1970, a depressão se estabelece com vigor no seio da medicina geral e se expande, por intermédio da mídia, a toda a população. Os laboratórios, as revistas, os jornais, a televisão, cumprem o seu papel.

Um psiquiatra americano, Mark Gold, escreveu em seu livro The good news about depression: "Você não poderia escolher um momento melhor na história humana para sentir-se infeliz" (apud EHRENBERG, 1998, p. 89). ${ }^{1}$

A relação entre a procura de um bem-estar e a droga não é privilégio de nosso século. É possível que tenha sempre acompanhado a humanidade. No século XIX, aparece o elogio da droga como verdadeiro antídoto contra o mal-estar da modernidade. Por um lado, favorecendo o surgimento de um

1. "Vous n'auriez pas pu choisir un meilleur moment dans l'histoire humaine pour vous sentir malheureux." 


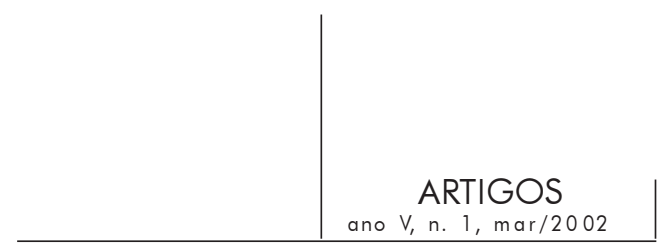

mundo solidário, no qual as barreiras da individualidade se atenuam, dando origem a comportamentos coletivos que reduzem a infelicidade da solidão e do desamparo, e, por outro lado, propiciando o bem-estar narcísico da auto-suficiência, da onipotência, reduzindo a vulnerabilidade e a insegurança, protegendo o indivíduo de seu sentimento de incapacidade e fragilidade frente à vida. $\mathrm{O}$ haxixe, a cocaína e o ópio passam a oferecer, portanto, novas formas de sociabilidade e de encontro entre os homens (Milner, 2000, p. 55-7).

O ópio se destacava como sendo capaz de atuar nos deprimidos gerando energia, sem, entretanto, ser um estimulante. Por um lado, acalmava os agitados e, por outro, dava energia aos desvitalizados.

$\mathrm{Na}$ época da descoberta da primeira substância antidepressiva moderna, a iproniazida, o ópio era considerado a substância mais eficaz contra a depressão. Para Ronald Kuhn, pesquisador suíço, o ópio oferecia o modelo apropriado para um antidepressivo. E ainda hoje muitos melancólicos apenas respondem aos opiáceos.

A iproniazida foi uma substância isolada para o tratamento da tuberculose que acabou por provar a sua eficácia não apenas no combate ao bacilo provocador da doença, mas também como estimulante do apetite, estimulador de energia e propiciador de um bem-estar geral. Entretanto, não apresentava as características do ópio. Kuhn empenha-se na procura de uma substância com essas características e acaba por chegar a um novo produto, a imipramina, que deu origem ao primeiro antidepressivo não estimulante. Partindo para pesquisar os anti-histamínicos que, como o ópio, apresentavam um efeito sedativo, seis meses após a publicação dos primeiros artigos sobre o sucesso da iproniazida, em setembro de 1957, anuncia a descoberta da nova substância, a imipramina, capaz de ser um sedativo para os considerados normais, porém produzindo um efeito de melhoria nos deprimidos. Afirma então:

Mesmo se o tratamento específico para os estados depressivos que temos encontrado não for o ideal, ele já vai longe nessa direção. Eu insisto sobre o termo específico, pois este medicamento restabelece largamente ou totalmente o que a doença deteriorou, a saber, não somente as funções e a capacidade mental, mas sobretudo o poder de experimentar. (apud KRAMER, 1994, p. 81) ${ }^{2}$

Kuhn, descobrindo os efeitos antidepressivos da imipramina, inaugura toda uma linhagem das drogas tricíclicas. Seu ponto de partida são a melancolia e a distinção endógeno e exógeno, biológico e psicogenético.

2. "Même si le traitement spécifique pour les états dépressifs que nous avons trouvé n'est pas idéal, il va déjà loin dans cette direction. J'insiste sur le terme spécifique, car ce médicament rétablit largement ou totalement ce que la maladie a détérioré, à savoir non seulement les fonctions et la capacité mentale, mais surtout le pouvoir d'éprouver.". 


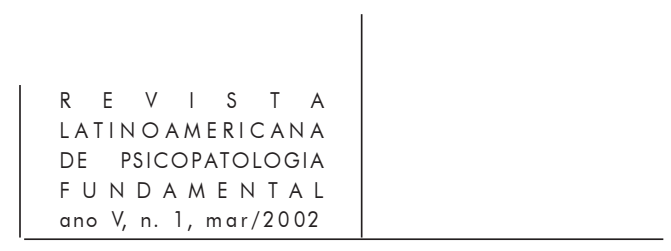

Ele se identifica com a tradição da psiquiatria fenomenológica. Esta trouxe à compreensão da melancolia um élan decisivo que "não veio (...) da biologia ou da bioquímica, mas, de maneira surpreendente, da filosofia". (apud EHRENBERG, 1998, p. 89$)^{3}$

Partindo da psicopatologia, recebendo a influência de Heidegger e de Binswanger, Kuhn se preocupa em precisar o diagnóstico da melancolia, procurando afastar as neuroses com sintomas depressivos para, então, testar a ação clínica da molécula. Os primeiros resultados são apresentados no Congresso Mundial de Psiquiatria, reunido em Zurich, em 6 de setembro de 1957. A imipramina, ainda que podendo atuar nas depressões ditas neuróticas, tem sua ação marcada sobretudo nas consideradas depressões endógenas típicas, onde se manifesta claramente uma perturbação vital e emocional (Ibid., p. 91-2).

Essas duas drogas abrem seus caminhos na psiquiatria atual. Entre 1955 e 1960, não só os congressos como as publicações sobre os psicotrópicos se multiplicam (Ibid., p. 95). O americano Nathan Kline, através da iproniazida, inicia a classe dos inibidores da monoamino oxidase (IMAO) (Ibid., p. 90). Ronald Kuhn, pela imipramina, inaugura toda a linhagem dos tricíclicos, como já mencionei. A serotonina e a noradrenalina, dois neurotransmissores, são os responsáveis pelas alterações do humor. Numerosas pesquisas procuram sintetizar moléculas mais específicas e eficazes. Em dezembro de 1987, surge o Prozac, graças ao trabalho conjunto de alguns pesquisadores, destacando-se David Wong e Bryan Molloy, que, em 1974, anunciam ser a fluoxetina um inibidor seletivo da recaptação da serotonina em cérebros de ratos (KRAMER, 1994, p. 96). O Prozac seria comercializado em 1987 e, cinco anos após seu lançamento, chegaria a ser tomado por mais da metade da população dos Estados Unidos (Ibid., p. 13).

O movimento de procurar a compreensão dos mecanismos psíquicos através do efeito de determinadas drogas, que funcionavam como verdadeiras sondas de pesquisa, no dizer de Peter Kramer, traduziu-se na elaboração da "teoria aminérgica (aminergique) da depressão" (Ibid., p. 82). O humor passou, então, a ser considerado como determinado pelas aminas biogênicas cerebrais, "quer dizer, substâncias químicas complexas (...) que contribuem para regular funções como o ritmo cardíaco, motilidade intestinal, estado de vigília e sono" (Ibid., p. 83).

O desenvolvimento das pesquisas acabou por demonstrar que essas duas drogas, a iproniazida e a imipramina, exerciam influências na transmissão de sinais entre células nervosas. A partir de diferentes mecanismos, acabavam por aumentar a quantidade

3. "Il se revendique de la tradition psychiatrique phénoménologique. Elle a apporté à la compréhension de la melancolie un élan décisif qui 'ne vint pas (...) de la biologie ou de la biochimie, mais, de façon surprenante, de la philosophie'." 


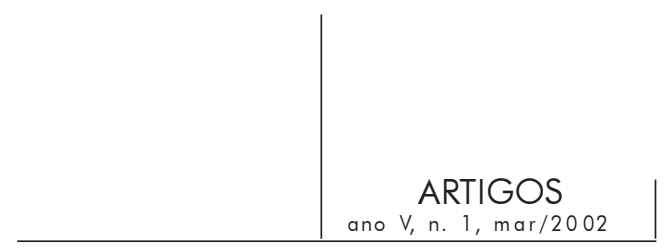

de neurotransmissores disponíveis em certas partes do cérebro, o que levou à conclusão de ser a depressão decorrente de uma deficiência de aminas. E, na impossibilidade de fornecer aminas, o que deveria ser tentado era evitar a sua destruição. A depressão equipara-se, então, a doenças cujo aparecimento depende do excesso ou carência de substâncias produzidas pelo organismo, como a diabete, o hipertireoidismo, etc.

Essa leitura que nos transmite a psiquiatria biológica tem muitas conseqüências, não apenas no nível do indivíduo, mas também em um plano social. No passado, a melancolia esteve, muito frequientemente, vinculada aos homens geniais. Todos nós nos lembramos do tratado de Aristóteles, Problemata XXX, onde o autor inicia a sua descrição do quadro, indagando, justamente, o porquê de os homens geniais acometidos desse sofrimento serem portadores da bile negra (PERES, 1996, p. 15). Hoje, a depressão se inscreve em um quadro de menos valia, traduzindo-se em termos de uma incapacidade para viver produzida pela insuficiência de uma substância.

Alain Ehrenberg (1998), na análise sociológica que realiza, nos diz que a depressão reflete a insuficiência do homem contemporâneo. Partindo de Freud e Pierre Janet, ele nos mostra que a linhagem freudiana enfatiza o conflito, enquanto a linhagem janetiana, a insuficiência. A psiquiatria apóia-se sobretudo nessa última, acolhendo, secundariamente, uma análise das circunstâncias de vida que afligem o homem moderno, ou seja, os seus conflitos. Na verdade, o sujeito, as particularidades de uma vida singular contam pouco. Existe um cérebro, existe um déficit de uma substância, e a suposição de correção dessa insuficiência pelo uso da droga. Enfatizase a inibição, as alterações na atividade e produtividade do indivíduo, menos a sua dor moral.

Nós sabemos, e a estatística, tão cara à psiquiatria, nos atesta, que a doença mental predominante nesse final de século é a depressão. Eu me pergunto por que os homens de hoje retêm menos serotonina e noradrenalina. Até onde pude chegar, não há uma resposta conclusiva, porque existe também um desconhecimento das razões pelas quais esse déficit altera a atividade e o humor. Supõe-se que a alteração de atividade e humor seja efeito da medicação, porém inexiste uma explicação do porquê dessa mudança; seriam fatores constitucionais, genéticos, em suma, uma hereditariedade biológica? Mas como situar essa hereditariedade em relação aos fatores circunstanciais da vida?

Parece-me que o uso das drogas levanta uma série de questões importantes para os psicanalistas, que, em princípio, devem estar atentos para escutar o que essas pílulas falam. E as depressões questionam fortemente a relação entre o normal e o patológico. É importante assinalar que Freud (1976, p. 81) nunca rejeitou a biologia e, nesse sentido, é bom lembrar a sua afirmativa: 


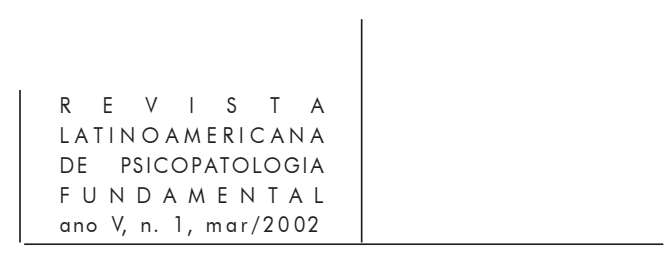

\begin{abstract}
A biologia é, verdadeiramente, uma terra de possibilidades ilimitadas. Podemos esperar que ela nos forneça as informações mais surpreendentes, e não podemos imaginar que respostas nos dará, dentro de poucas dezenas de anos, as questões que lhe formulamos.
\end{abstract}

Tal expectativa, contudo, não o afastou do seu caminho, mantendo intocada a sua crença na força e no poder da palavra. Na verdade, devemos a Lacan, com a sua leitura de um inconsciente estruturado como linguagem e a introdução da psicanálise no universo estruturalista, o total afastamento da psicanálise da biologia. É curioso que o apogeu da psicanálise francesa segue em paralelo com o surgimento dos psicofármacos.

O mundo em que as drogas predominam é o mundo do esquecimento e da artificialidade dos vínculos. Assim, o homem pode drogar-se para esquecer as misérias da vida e pode, também, drogar-se para estabelecer vínculos artificialmente solidários e alegres. Existe ainda a procura da euforia, que pode ensejar momentaneamente uma maior criatividade e produtividade. Mas o homem, igualmente, pode medicar-se para escapar do sofrimento e desfrutar de uma certa felicidade. Não é por acaso que o Prozac recebeu o apelido de pílula da felicidade.

Psicanálise e medicina seguem linhas de raciocínio absolutamente distintas; enquanto a primeira privilegia a subjetividade e vai buscar, nas palavras dos pacientes, indicadores de uma má estruturação egóica, uma deficiente organização narcísica; a psiquiatria parte em busca de uma suposta objetividade científica, nos indicadores que a biologia fornece do funcionamento cerebral, nas falhas dos neurotransmissores, a causa de uma doença. É o efeito produzido por uma nova molécula que vai indicar a sua dimensão terapêutica. Enquanto a psiquiatria engloba os pacientes em categorias diagnósticas e os define face à reação a determinada droga, a psicanálise os singulariza, tomando-os em sua dimensão individual, e valoriza não os seus neurotransmissores, porém os seus conflitos.

Para nós, psicanalistas, a depressão decorre de uma alteração narcísica. Freud, considerando a multiplicidade de suas manifestações (chegou a referir-se a ela de doze maneiras distintas) (PERES, 1996, p. 28-9), não deixou de nos indicar a existência de uma neurose do narcisismo. E, sendo o narcisismo uma etapa constitutiva do "eu", é uma má estruturação egóica que responde a essa afecção. O paciente deprimido é uma pessoa que vive submergido na perda. Nós sabemos que, como seres humanos, seres falantes, inseridos no universo simbólico, estamos sendo regidos pelo império de uma perda proveniente de uma ruptura com a ordem da natureza. Nessa passagem, natureza-cultura, o homem ganha, mas, em primeiro lugar, sofre a ausência de um destino apenas traçado pelas leis da natureza, pelas leis da biologia. O universo simbólico, as leis do significante ou, ainda, as palavras contaminam, alteram e influem o próprio funcionamento do nosso corpo e de seus órgãos constitutivos, como uma perversão da natureza. 


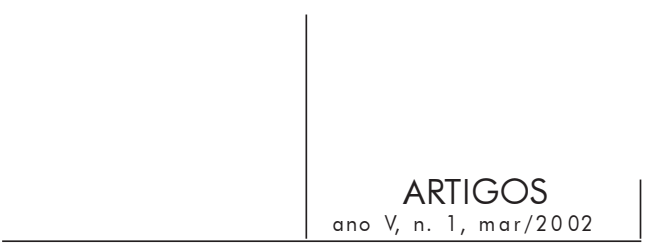

O deprimido é aquele para quem, no estabelecimento dessa falta constitutiva, algo claudicou, cujos reflexos se fazem sentir na estruturação do seu "eu", do seu narcisismo, através de uma luta entre um eu-ideal frágil e um ideal-do-eu implacável, pela crueldade de um superego gerador de um sentimento de culpa devastador. A auto-acusação, a auto-recriminação estão sempre presentes. Em verdade, ele é um enlutado com a vida, atormentado por uma perda que ele nem sabe qual foi, mas que faz buraco em sua existência, marcando uma dimensão de desamparo. Se tomamos sua palavra, podemos sintetizar o seu sofrimento na afirmativa mais generalizada da perda de sentido na vida. E não podemos esquecer que o sentido nos é dado pela nossa dimensão discursiva. É nosso imaginário, transportado em palavras, que diz do nosso sentido na vida.

Sabemos que o momento atual, marcado por uma acelerada alteração nos valores, defrontando homens e mulheres com um processo crescente de instabilidade através dos sucessivos processos de libertação - liberdade sexual, libertação das mulheres, rompimento com padrões tradicionais de vinculação à família, à religião e, sobretudo, marcando a responsabilidade do indivíduo pelo seu desempenho frente à vida - acentua, por um lado, o sentimento de desamparo e, por outro, gera uma crise de identidade. Seu lugar não é mais marcado por uma classe social seguindo uma tradição familiar. O homem está livre, porém sua liberdade é ilusória, na medida em que muitas vezes lhe são negadas as condições mínimas para viver sua liberdade. Para citar um só exemplo, consideremos a cada vez mais crescente ameaça de desemprego. Assistimos a um crescente individualismo versus uma globalização massificante (cf. PERES, 1999, p. 11-26).

Esse é um quadro absolutamente sumário para pensar o porquê do aumento de deprimidos no mundo atual.

Vemos, então, quão distintos são os enfoques da psiquiatria biológica e da psicanálise, porém ambos preocupados em minorar o sofrimento humano. A primeira pesquisa um déficit orgânico, a segunda, uma dor moral, a dor psíquica.

Amparados por um potente trabalho de propaganda, onde cifras milionárias alimentam os laboratórios, as pílulas crescem em prestígio, ao tempo em que a psicanálise se retrai. A interrogação que se coloca é a seguinte: pode a psicanálise ignorar os avanços da neurociência e, por outro lado, a psiquiatria abandonar a dor moral? Não creio. E, assim sendo, é importante precisar alguns aspectos que especialmente tocam a nós, psicanalistas.

O trabalho conjunto entre a psicanálise e a psiquiatria se faz, sobretudo, com pacientes psicóticos graves e neuróticos com ameaça de suicídio. Em princípio, o psicanalista solicita a intervenção médica nesses casos. Pode ocorrer, ainda, que o indivíduo procure a análise por indicação médica e, muitas vezes, já venha medicado. Mas existem também situações em que o próprio paciente, por efeito da mídia, de 


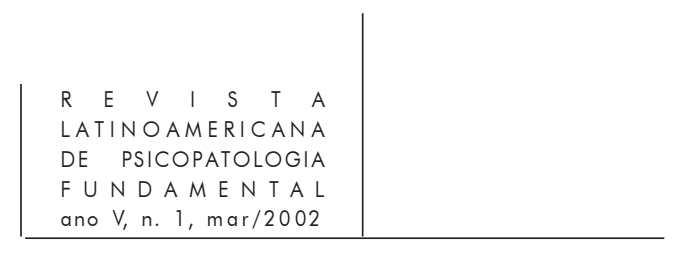

numerosas reportagens em revistas e na televisão, solicita a medicação. A neurose de angústia, como bem definiu Freud, batizada na atualidade como síndrome de pânico, enquadra-se, com muita freqüência, nessa categoria.

O que me parece extremamente importante é que o psicanalista possa estar ciente dos efeitos, na sua prática, quando há essa interferência, e, sobretudo, ficar atento para, ele próprio, não entrar na sedução da droga e desenvolver o raciocínio de que os pacientes medicados podem facilitar a condução da análise. Não quero dizer que a droga é sempre nefasta, nem eliminar a sua eficácia como alívio de sofrimento, porém é importante estarmos atentos para algumas interrogações que ela possa nos suscitar. Muitas vezes, é a própria angústia do analista, ao suportar a angústia do paciente, que o leva a encaminhá-lo. O analista se sente amparado em companhia do psiquiatra, situação essa que observamos, com muita freqüência, naqueles que precocemente se colocam como analistas.

No capítulo XXIV, do livro V, intitulado "Transferência e sugestão", Lacan (1999, p. 435-50) nos dá algumas boas pistas para pensar essa questão. Aliás, toda a análise feita, ainda nesse seminário, da diferença entre a necessidade, a demanda e o desejo é de extrema importância.

Sabemos que a transferência situa-se no cerne da cura analítica e que, por sua vez, ela é sustentada pela posição que o analista ocupa em relação ao saber, ou seja, posição de suposto-saber. Nesse sentido, a transferência não pode ser confundida com a sugestão. A posição do médico é outra: ele ocupa a posição do saber, atende à demanda do paciente de dar-lhe algo que o satisfaça, ou seja, satisfaz a sua necessidade, atuando, também, no nível da sugestão. Nenhum de nós ignora o efeito placebo contido em toda medicação.

Em seus trabalhos datados dos anos 1950, Sarwer-Foner se preocupa em dissociar efeitos dos psicotrópicos e a acolhida desses efeitos pelo paciente. Ele estabelece que esses medicamentos propiciam, claro, uma redução sintomática, mas que esta será vivida pelo paciente tanto como um benefício de retomada de controle sobre si mesmo, como uma diminuição invalidante de seu espaço psíquico. Ele mostra como, no final das contas, é das atitudes dos médicos e enfermeiros que esta vivência poderá bascular de um sentido ao outro. (KAPSAMBELIS, 1994, p. 39) ${ }^{4}$

4. "Dans ses travaux datant des années 1950, Sarwer-Foner s'attache à dissocier effets de psychotropes et accueil de ces effets par le patient. Il établit que ces médicaments apportent, certes, une réduction symptomatique, mais que celle-ci sera vécue par le patient aussi bien comme une bénéfique reprise de contrôle de soi-même, que comme une diminution invalidante de son espace psychique. Il montre comment, en fin de compte, c'est des attitudes des médecins et des infirmiers que ce vécu pourra basculer dans un sens ou dans un autre." 


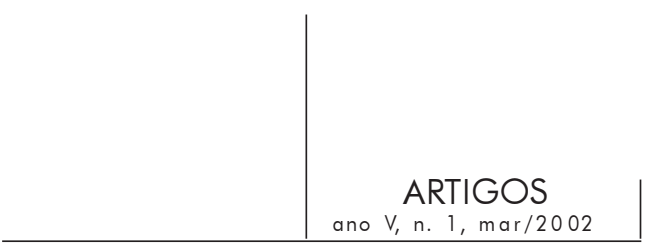

Contudo, a droga é sempre indicada como elemento principal da cura, ela chega como um objeto que pode obturar uma falta.

Novamente nos defrontamos com a total disparidade de uma ou outra conduta.

Para o psicanalista, toda demanda é demanda de uma necessidade e demanda de amor. Quando essas duas dimensões ficam pouco destacadas, confundidas mesmo, Lacan aponta uma ambigüidade entre a transferência e a sugestão, sempre indicada na obra de Freud.

Para Freud, a transferência é uma sugestão que sofre os efeitos de uma interpretação. Interpretar a sugestão é indicar-lhe um outro plano contido na própria sugestão. A transferência estaria sempre situada em potencial.

A transferência já é, potencialmente, uma análise da sugestão, ela própria é a possibilidade da análise do sujeito, é a articulação secundária daquilo que, na sugestão, impõe-se pura e simplesmente no sujeito. (LACAN, 1999, p. 439)

Considerando que a transferência é a possibilidade de uma outra articulação significante, distinta, portanto, da que encerra o sujeito na demanda, atender a essa demanda implica não apenas a sugestão pura e simples, cuja eficácia é de pouca duração, mas também em um enfraquecimento da transferência,que, apenas pelo efeito de uma interpretação, pela possibilidade de um novo sentido, se constitui.

Impõe-se a seguinte questão: É por fragilidade transferencial ou por falha interpretativa que o apelo às medicações e a solicitação ao psiquiatra têm se acentuado? Algo da ordem de um acting out perpetrado pelo próprio analista?

O encaminhamento, pelo analista, de um paciente em análise ao psiquiatra implica um ato de sugestão: "Estou lhe enviando a alguém que sabe o que você tem e que vai lhe dar algo que vai satisfazê-lo, curá-lo". A medicina tem sempre uma promessa de cura. Existe também o risco da medicalização da própria prática analítica, transformando um luto, um sofrimento por determinadas circunstâncias da vida, um rompimento de relações afetivas, uma crise conjugal, uma dificuldade com a maternidade ou paternidade em doença, ou seja, igualando a tristeza à depressão.

Outros pontos importantes são o acompanhamento da alteração discursiva do paciente, quando medicado, e a interrogação quanto a alterações na sua dimensão desejante. É muito freqüente observarmos, da parte do analisante, a sua insatisfação com a droga como algo intrusivo de que ele deseja libertar-se. Ainda aqui, Lacan nos dá a pista, ao nos indicar que algo resiste quando da junção da demanda de uma necessidade com a demanda de amor, ou seja, entre a transferência e a sugestão, e que essa resistência se presentifica exatamente pelo desejo. O desejo de o sujeito ter seu próprio desejo.

Nós sabemos que um dos efeitos da medicação é produzir uma alteração de identidade. Já ouvi de pacientes em uso de medicação antidepressiva: "Já não sei quem eu sou, se sou o que era antes do remédio ou o que sou agora". "Não me 


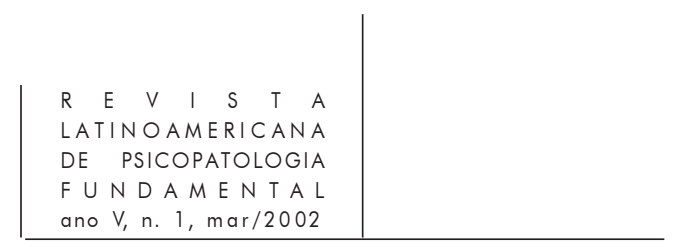

reconheço sem a minha tristeza". "Sinto uma indiferença frente aos fatos que me faz pensar que sou outra pessoa". "Tenho medo de parar a medicação e perder esta facilidade para falar e escrever que agora tenho; ela não é minha, é do remédio". Essas e muitas outras falas podem atestar alterações de identidade e modificar a posição desejante do sujeito; isso sem entrarmos na questão dos efeitos secundários, que atuam no nível do corpo e que também se revestem de preocupações. A todas essas questões o psicanalista tem que estar atento.

Freud nos mostrou o poder curativo da palavra; Lacan, entre outros méritos, teve o de restaurar o lugar dessa palavra. E nós, como estamos seguindo? Será que as recentes descobertas da neurobiologia alteram o poder da palavra? De nenhuma maneira.

Creio que dois fatores são importantes, nesse momento, e nessa relação psicanálise e droga: tempo e dinheiro. Diante dessa corrida acelerada contra o tempo, e das limitações financeiras que uma permanente situação de crise impõe, a psicanálise tem que produzir saídas mais satisfatórias. Nós sabemos da importância do número de sessões, da freqüência dos atendimentos e da fala do analista no suporte de situações de maior angústia e depressão. Esse tema, contudo, nos abre espaço para outras reflexões que o tempo de que aqui dispomos não nos permite. E, por outro lado, devemos estar atentos para o empobrecimento do espaço teórico que o complexo médico-industrial promove.

Gostaria apenas, para concluir, de lançar uma interrogação: Como está a crença no inconsciente entre os psicanalistas?

\section{Referências}

Belaga, Guillermo. Formas clínicas. Buenos Aires: Descartes, 1999.

EhrenBerg, Alain. La fatique d'être soi. Dépression et societé. Paris: Odile Jacob, 1998.

Freud, Sigmund (1920-1922). Más allá del principio del placer. Trad. José Etcheverry. In:

Obras completas. Buenos Aires: Amorrortu, 1976. v. 18.

(1920-1922). Além do princípio do prazer. Trad. Christiano Monteiro Oiticica. ESB.

Rio de Janeiro: Imago, 1976.

Healy, David. The anti-depressant era. Cambridge: Harvard University Press, 1997.

Kapsambelis, Vassilis. Les médicaments du narcissisme, métapsychologie des neuroleptiques. Ouvrage réalisé par le Département Communication Synthélabo. Paris: 1994. (Col. Les Empêcheurs de Penser en Rond).

Kramer, Peter. Prozac: le bonheur sur ordonnance?. Trad. Françoise Fauchet. Paris: F1rst, 1994.

LaCAn, Jacques. O seminário. Livro $V-$ As formações do inconsciente. Texto estabelecido por Jacques Alain Miller. Trad. Vera Ribeiro. Rio de Janeiro: Jorge Zahar, 1999. 


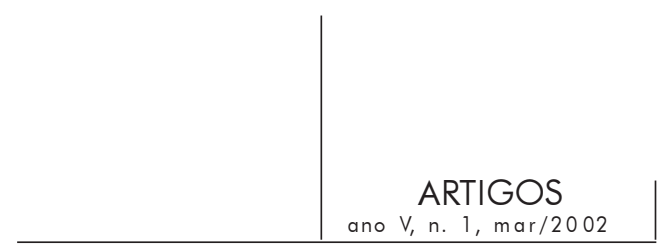

La tentation du bonheur. Magazine littéraire, Paris, n. 389, août 2000.

LAmbert, P.-A. Psychanalyse et psycho-pharmacologie. Paris/Barcelona: Masson, 1990.

Lipovetsky, Gustavo. Los dilemas de la psiquiatria. Zona Érogena, Buenos Aires, n. 45, p. 10-12, fev. 2000.

Milner, Max. Les orfeliens du paradis. Magazin littéraire, Paris, n. 389, p. 55-7, 2000.

Peres, Urania Tourinho. Mosaico de letras: ensaios de psicanálise. São Paulo: Escuta, 1999.

(Org.). Melancolia. São Paulo: Escuta, 1996.

Roudinesco, Elizabeth. Psicoanálisis vs. Prozac. Zona Érogena, Buenos Aires, n. 44, p. 68, nov. 1999.

SAIDón, Osvaldo. Recetas. Zona Érogena, Buenos Aires, n. 45, p. 14-16, fev. 2000.

\section{Resumos}

A través de un breve histórico del surgimiento y del desarrollo de los antidepresivos vamos a llegar a confrontar dos líneas en el abordaje de las depresiones, consideradas como la "enfermedad" por excelencia del hombre contemporáneo. El psicoanálisis a partir de la noción de conflicto y la psiquiatría a partir de una insuficiencia biológica, un déficit de neurotransmisores. Es así que dos líneas de pensamiento se desenvuelven marcando posiciones diferentes: una privilegiando la subjetividad del paciente, otra buscando la objetividad científica.

Nos preguntamos cómo el psicoanálisis debe situarse frente a la creciente medicalización de la vida y frente a los adelantos de la neurobiología. Vamos a presentar también un camino teórico que nos fue facilitado por Jacques Lacan marcando la distinción entre transferencia y sugestión.

Palabras clave: Psicoanálisis, psiquiatría, transferencia, sugestión, conflicto, neurotransmisores

Au travers d'un bref historique de l'apparition et du développement des antidépressifs, nous allons arriver à un affrontement entre les deux lignes d'approche des dépressions, considérées comme la "maladie" par excellence de l'homme contemporain. La psychanalyse prend comme point de départ la notion du conflit et la psychiatrie une insuffisance biologique, un déficit de neurotransmisseurs. C'est ainsi que deux lignes de raisonnement se développent en prenant des positions distinctes, l'une privilégiant la subjectivité du patient et l'autre la recherche d'une objectivité scientifique.

Nous nous demandons comment la psychanalyse doit se situer face à la croissante médicalisation de la vie et des avancées de la neurobiologie. Nous allons présenter un chemin théorique qui nous est facilité par Jacques Lacan quand il marque la distinction entre le transfert et la suggestion.

Mots clés: Psychanalyse, psychiatrie, transfert, suggestion, conflit, neurotransmetteurs 


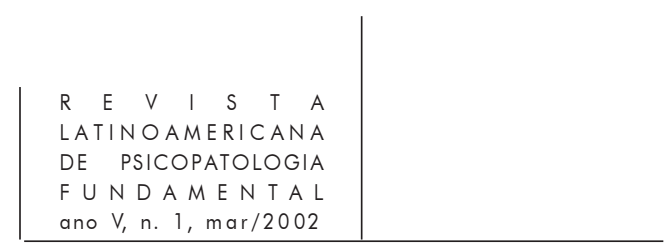

Through a brief description of the development and evolution of anti-depressants, the confrontation between the two lines of approach are described in relation to depression, considered the "disease" par excellence of contemporary life. While the starting point for psychoanalysis is the notion of conflict, psychiatry presupposes biological insufficiency, or deficits in neurotransmission. Two lines of thinking are therefore developed, indicating distinct positions, one privileging the patient's subjectivity, and the other stressing the point of view of scientific objectivity.

The question we ask is how should psychoanalysis position itself in view of the increasing medicalization of life and the advances of neurobiology. In response, we present a theoretical path opened up by Jacques Lacan, where he discusses the distinction between transference and suggestion.

Key words: Psychoanalysis, psychiatry, transference, suggestion, conflict, neurotransmission 